\title{
Recent Patterns in Shared Decision Making for Prostate- Specific Antigen Testing in the United States
}

\author{
Stacey A. Fedewa, $\mathrm{PbD}, \mathrm{MPH}$ \\ Ted Gansler, MD, MBA, MPH \\ Robert Smith, $P b D^{2}$ \\ Ann Goding Sauer, MSPH \\ Richard Wender, $M D^{2}$ \\ Otis W. Brawley, MD, MPH \\ Abmedin Jemal, DVM, $P b D^{1}$ \\ 'Intramural Research Department, Amer- \\ ican Cancer Society, Atlanta, Georiga \\ ${ }^{2}$ Cancer Control Department, American \\ Cancer Society, Atlanta, Georgia \\ ${ }^{3}$ Office of the Chief Medical Officer, Amer- \\ ican Cancer Society, Atlanta, Georgia
}

Conflicts of interest: authors report none.

\section{CORRESPONDING AUTHOR}

Stacey A. Fedewa, PhD, MPH

250 Williams Street

Atlanta, GA 30303

stacey.fedewa@cancer.org

\begin{abstract}
PURPOSE Previous studies report infrequent use of shared decision making for prostate-specific antigen (PSA) testing. It is unknown whether this pattern has changed recently considering increased emphasis on shared decision making in prostate cancer screening recommendations. Thus, the objective of this study is to examine recent changes in shared decision making.
\end{abstract}

METHODS We conducted a retrospective cross-sectional study among men aged 50 years and older in the United States using 2010 and 2015 National Health Interview Survey (NHIS) data $(n=9,598)$. Changes in receipt of shared decision making were expressed as adjusted prevalence ratios (aPR) and 95\% confidence intervals (CI). Analyses were stratified on PSA testing (recent [in the past year] or no testing). Elements of shared decision making assessed included the patient being informed about the advantages only, advantages and disadvantages, and full shared decision making (advantages, disadvantages, and uncertainties).

RESULTS Among men with recent PSA testing, 58.5\% and 62.6\% reported having received $\geq 1$ element of shared decision making in 2010 and 2015, respectively ( $P=.054$, aPR $=1.04 ; 95 \% \mathrm{Cl}, 0.98-1.11)$. Between 2010 and 2015, being told only about the advantages of PSA testing significantly declined (aPR $=0.82$; $95 \% \mathrm{Cl}, 0.71-0.96)$ and full shared decision making prevalence significantly increased $(\mathrm{aPR}=1.51 ; 95 \% \mathrm{Cl}, 1.28-1.79)$ in recently tested men. Among men without prior PSA testing, $10 \%$ reported $\geq 1$ element of shared decision making, which did not change with time.

CONCLUSION Between 2010 and 2015, there was no increase in shared decision making among men with recent PSA testing though there was a shift away from only being told about the advantages of PSA testing towards full shared decision making. Many men receiving PSA testing did not receive shared decision making.

Ann Fam Med 2018;16:139-144. https://doi.org/10.1370/afm.2200.

\section{INTRODUCTION}

$\mathrm{R}$ ecommendations for prostate-specific antigen (PSA) screening for prostate cancer have changed in the past several years and vary by the recommending body..$^{1-5}$ There is virtual consensus, however, that PSA testing should not occur without shared decision making and that men aged $\geq 75$ years or those with limited life expectancy should not receive PSA testing. ${ }^{3-6}$ Shared decision making is a process in which clinicians convey what is known about a medical intervention such as a screening test. In addition, patients share their needs and preferences when choosing whether to pursue an intervention. ${ }^{7}$

Current guidelines from the American Cancer Society (ACS), American Urological Association (AUA), and American College of Physicians (ACP), strongly emphasize the use of shared decision making for PSA testing in men beginning at age 50 or 55 years. $^{3-5}$ In 2012, the US Preventive Services Task Force (USPSTF) recommended against routine PSA testing for men of all ages (without discussion), though to a certain degree, these recommendations are in accord with others, stating that shared decision making should be employed if patients request and physicians continue to offer PSA 
testing. ${ }^{1}$ In April 2017, the USPSTF released an updated draft of their recommendations, stating that clinicians should inform men aged 55 to 69 years about the potential benefits and harms of PSA testing, and that the decision to undergo testing is an individual one. ${ }^{2}$

Previous studies have shown that most men undergoing PSA testing reported either no discussion or only heard about the benefits of the test. ${ }^{8,9}$ Other studies have shown variability and inadequacy of shared decision making. ${ }^{9-13}$ It is not known, however, whether the use of shared decision making has changed in the wake of the shifting PSA-screening recommendations and practices at the national level. ${ }^{14}$ Thus, the objective of this study is to identify any changes in self-reported shared decision making for PSA testing between the 2010 and 2015 National Health Interview Survey (NHIS) data.

\section{METHODS}

Our retrospective cross-sectional study used data collected in the NHIS, a nationally representative, in-person survey of noninstitutionalized people. Shared decision making questions were included in the 2010 and 2015 survey data used in this study. The survey response rates were $60.8 \%$ for 2010 and $55.2 \%$ for $2015 .{ }^{15}$ Male respondents aged $\geq 50$ years were selected $(n=12,561)$. Men who reported a history of prostate cancer $(n=680)$, were missing data on key variables $(n=1,649)$, or had PSA testing for nonroutine reasons $(n=634)$ were excluded, resulting in an analytic population of 9,598 men (Supplemental Figure 1, available at http://www.annfammed. org/content/16/2/139/suppl/DC1/). The study used de-identified, publicly available data and did not require institutional review board approval.

\section{Measures}

We defined shared decision making using a framework similar to that employed by Han and collegues, ${ }^{8}$ which includes necessary components of shared decision making according to ACS and AUA recommendations. ${ }^{3,4}$ These components include informing patients about the advantages and disadvantages of PSA testing, as well as uncertainties regarding the test.

Details of the NHIS questionnaire and our categorization of the outcome are presented in Supplemental Table 1 (available at http://www.annfammed.org/ content/16/2/139/suppl/DC1/). Briefly, respondents were asked 3 questions about whether a physician had ever discussed (1) the advantages and (2) the disadvantages of testing, and (3) that some doctors disagree about the benefits of PSA testing. ${ }^{16}$ We grouped completeness of shared decision making into 4 mutually exclusive categories: none, full, advantages only, advantages and disadvantages. Estimates for remaining combinations were unstable and grouped together to form an "other" category. The 2015 survey also included a question about who suggested PSA testing (physician, self, or someone else).

The primary independent variable was the survey year $(2010,2015)$. Covariates included age, educational attainment, race/ethnicity, immigration status, and health insurance type/status. Having a first-degree family history of prostate cancer and having visited a specialist or primary care physician in the past year were also considered.

\section{Statistical Analysis}

We used $\chi^{2}$ tests $(\alpha=.05)$ to examine differences in respondent characteristics by survey year and shared decision making categories. Analyses of shared decision making were stratified on PSA testing history grouped as never tested, nonrecent PSA test (in the past 2-5 years), and recent PSA test (during the past year).

To determine whether potential changes between 2010 and 2015 persisted after adjustment for covariates and to examine the association between shared decision making and sociodemographic factors, adjusted prevalence ratios (aPR) and corresponding 95\% confidence intervals $(\mathrm{CI})$ were estimated using logistic regression models with predicted marginal probabilities. ${ }^{17}$

Several secondary analyses were conducted. The definition of recent PSA testing was broadened to include men who had tests in the past 2 years. ${ }^{3}$ Family history of prostate cancer was also included in models to determine if that altered results. And, for men with recent PSA testing, we restricted analyses to men reporting a primary care physician or specialist visit in the past 12 months. All analyses were conducted in SAS-callable SUDAAN, version 9.4 (RTI International) and accounted for the survey design.

\section{RESULTS}

Of the 9,598 participants included, approximately twothirds were aged 50 to 64 years, three-quarters were white, and the majority had insurance. (Supplemental Table 2, available at http://www.annfammed.org/ content/16/2/139/suppl/DC1/.) In the 2010 and 2015 surveys, $38.1 \%$ and $32.1 \%$ of men reported PSA testing in the past year, respectively. In the 2010 survey, 19.2\% of men reported PSA testing $>1$ year ago, increasing to 23.2\% in 2015. (Supplemental Table 2.)

Receipt of $\geq 1$ shared decision making element was similar in 2010 (37.2\%) and 2015 (37.9\%) among all men $(P=.958)$ (Figure 1a), but increased slightly from $58.5 \%$ to $62.6 \%(P=.054)$ in men with recent PSA 
testing (Figure $1 \mathrm{~b}$ ). Among men with nonrecent PSA testing, $54.6 \%$ reported receipt of $\geq 1$ shared decision making component in 2010 compared to $56.8 \%$ in 2015 $(P=.448)$ (Figure 1c). Receipt of $\geq 1$ shared decision making component was infrequently reported by men with no previous PSA testing, regardless of the survey year (2010: 10.4\%; 2015: 10.3\%, $P=.986$ ) (Figure 1d).

Among men with recent PSA testing, being told about the advantages only was the most commonly reported shared decision making situation. The proportion of men in this category did not change in unadjusted analysis (2010: 23.9\%, 2015: 20.9\%, $P=$ .811) (Table 1), but significantly declined in 2015 in adjusted analysis $(\mathrm{aPR}=0.82 ; 95 \% \mathrm{CI}, 0.71-0.96)$ (Table 2). The proportion of men with recent PSA testing reporting full shared decision making increased

\section{Figures 1a-d. Receipt of shared decision making among men by PSA testing category, NHIS 2010 and 2015.}

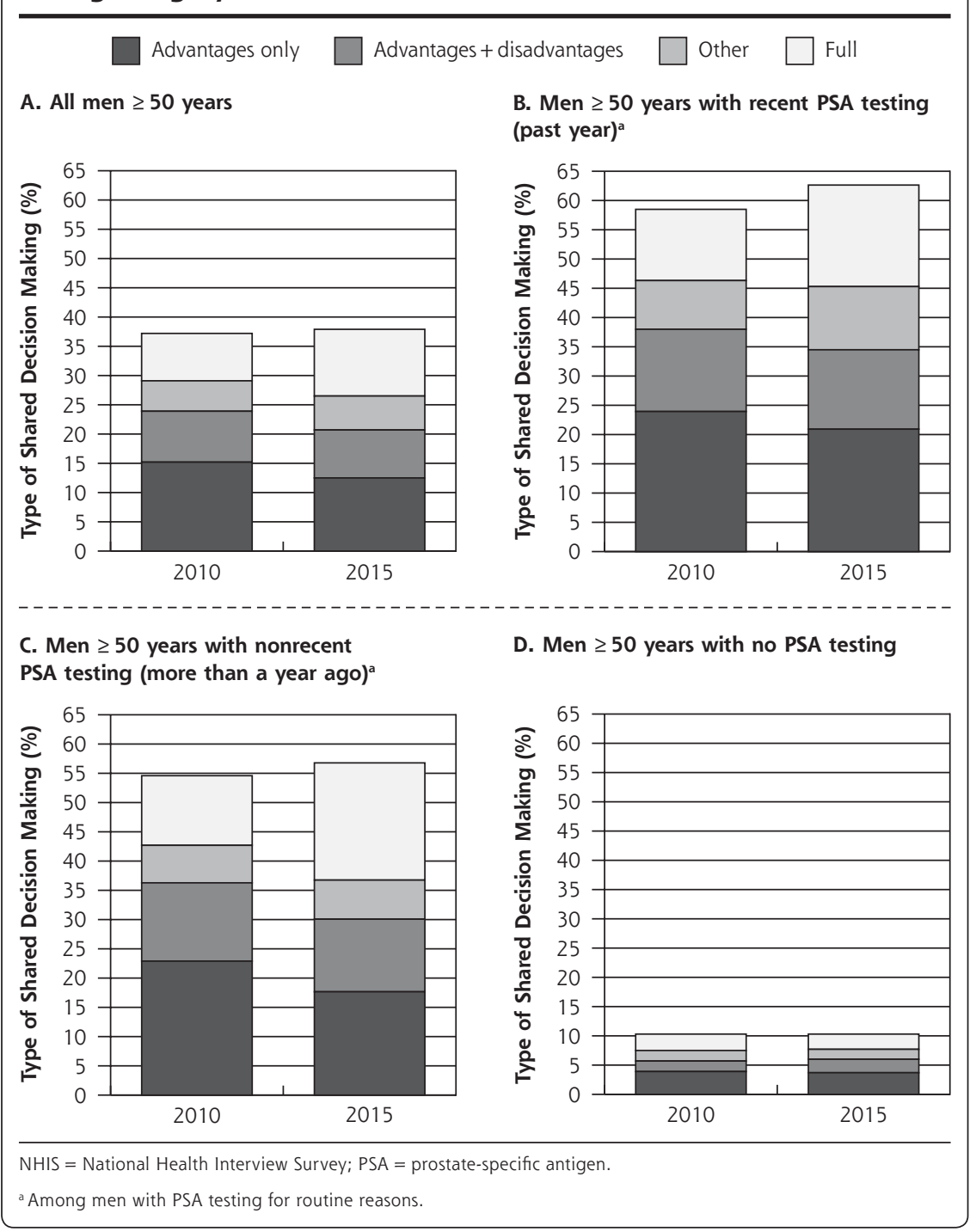

from $12.2 \%$ in 2010 to $17.4 \%$ in 2015 in unadjusted analysis $(P<.001)$ and in adjusted analyses, it was $51 \%$ higher in 2015 than in $2010(\mathrm{aPR}=1.51 ; 95 \% \mathrm{CI}, 1.28$ 1.79). Similar patterns were observed among men with nonrecent testing (Table 2) and among those with PSA testing in the past 2 years (Supplemental Table 3, available at http://www.annfammed.org/content/16/2/139/ suppl/DC1/). There was no change in patients being told only about the advantages or in receiving full shared decision making among men who had never had a PSA test (Table 2). Inclusion of family history did not alter results (data not shown).

When full shared decision making was examined according to sociodemographic factors, it was significantly less common in men without a high school diploma relative to college graduates in adjusted analyses (Supplemental Table 4, available at http://www.annfammed.org/ content/16/2/139/suppl/DC1/). For example, among men with recent PSA testing, those without a high school diploma were about one-half as likely as men with a college degree to report full shared decision making $(\mathrm{aPR}=0.45 ; 95 \% \mathrm{CI}$, $0.28-0.71$ ).

In 2015, men with recent PSA testing indicated the test was suggested by their physician $(85.0 \%)$, themselves $(11.9 \%)$, or someone else (3.1\%) (Supplemental Table 5, available at http:// www.annfammed.org/ content/16/2/139/suppl/DC1/).

\section{DISCUSSION}

In this nationally representative study, a similar proportion (about $60 \%$ ) of men with recent PSA testing reported $\geq 1$ shared decision-making element in 2010 and 2015. During this time, there was a slight shift away from a discussion of only the advantages and toward full shared decision making (discussion of advantages, disadvantages, and uncertainties) among men recently tested. Only 1 in 
Table 1. Receipt of Shared Decision Making Among Men by Testing History and Age, NHIS 2010 and 2015 (n=9,598)

\begin{tabular}{|c|c|c|c|c|c|c|c|c|}
\hline \multirow{2}{*}{$\begin{array}{l}\text { Testing } \\
\text { History } \\
\text { and Age }\end{array}$} & \multicolumn{2}{|c|}{$\begin{array}{c}\geq 1 \text { Element } \\
\text { of SDM }\end{array}$} & \multicolumn{2}{|c|}{ Advantages } & \multicolumn{2}{|c|}{$\begin{array}{c}\text { Advantages and } \\
\text { Disadvantages }\end{array}$} & \multicolumn{2}{|c|}{ Full } \\
\hline & 2010 & 2015 & 2010 & 2015 & 2010 & 2015 & 2010 & 2015 \\
\hline \multicolumn{9}{|c|}{ Among men with recent PSA testing $(n=3,079), \%$} \\
\hline$\geq 50 y$ & 58.5 & 62.6 & 23.9 & 20.9 & 14.1 & 13.6 & $12.2^{\mathrm{a}}$ & $17.4^{\mathrm{a}}$ \\
\hline $50-64$ y & 58.3 & 63.4 & 23.7 & 21.3 & 14.6 & 15.0 & $11.6^{a}$ & $17.3^{a}$ \\
\hline $65-74$ y & 57.4 & 63.5 & 23.3 & 19.8 & 14.1 & 12.1 & $13.6^{\mathrm{a}}$ & $19.0^{\mathrm{a}}$ \\
\hline$\geq 75$ y & 61.7 & 58.0 & 26.6 & 22.0 & 11.7 & 11.4 & 11.8 & 13.9 \\
\hline \multicolumn{9}{|c|}{ Among men with nonrecent PSA testing ( $n=2,104), \%$} \\
\hline$\geq 50 y$ & 54.6 & 56.8 & $22.9^{\mathrm{a}}$ & $17.7^{\mathrm{a}}$ & 13.4 & 12.4 & $11.9^{a}$ & $20.0^{a}$ \\
\hline $50-64 y$ & 56.5 & 55.1 & $23.2^{\mathrm{a}}$ & $15.7^{a}$ & 13.3 & 12.2 & 14.3 & 19.7 \\
\hline $65-74$ y & $48.9^{a}$ & $59.4^{a}$ & 20.9 & 21.3 & 14.8 & 13.3 & $7.0^{b}$ & 19.8 \\
\hline$\geq 75 y$ & 55.4 & 58.7 & 24.7 & 18.5 & 11.5 & 11.7 & $9.6^{a}$ & $21.5^{a}$ \\
\hline \multicolumn{9}{|c|}{ Among men with no PSA testing $(n=4,415), \%$} \\
\hline$\geq 50 y$ & 10.4 & 10.3 & 3.9 & 3.7 & 2.1 & 1.8 & 2.8 & 2.6 \\
\hline $50-64$ y & 10.4 & 10.0 & 4.0 & 3.5 & 1.8 & 2.4 & 2.6 & 3.1 \\
\hline $65-74$ y & 10.6 & 9.8 & $4.8^{b}$ & 5.3 & $1.5^{b}$ & $1.5^{b}$ & $3.0^{b}$ & 1.6 \\
\hline$\geq 75$ y & 10.0 & 9.7 & $2.1^{b}$ & $1.9^{b}$ & $2.2^{b}$ & $2.2^{b}$ & $4.6^{b}$ & $1.0^{\mathrm{b}}$ \\
\hline
\end{tabular}

the disparities in shared decision making associated with educational attainment.

The lack of change in shared decision making among men who did not have PSA testing is somewhat unexpected given that use of decision aids for shared decision making has been associated with a lower likelihood of testing ${ }^{30}$ and that PSA testing rates declined between 2010 and 2013 (then plateaued between 20132015). ${ }^{14,31}$ There is conflicting evidence, however, about the long-term influence of shared decision making on prostate cancer screening behaviors. ${ }^{23}$ It is plausible that some physicians may have backed away from shared decision making if they applied greater weight to 2012 USPSTF recommendations against routine testing

10 men with no PSA tests reported receiving $\geq 1$ element of shared decision making, with no change from 2010 to 2015.

Receipt of any form of shared decision making did not change among men with recent PSA testing, though the proportion of men reporting full shared decision making modestly increased between 2010 and 2015. The latter may reflect a growing recognition of conflicting results from studies of the benefits of PSA testing on prostate cancer mortality ${ }^{18,19}$ and the 2012 USPSTF recommendation against routine PSA testing that was widely covered in the media and medical literature. ${ }^{20-22}$ Despite the observed change in full shared decision making, the proportion of men with recent PSA testing who reported full shared decision making was still relatively small by the end of the study period (17\% in 2015) and being told the advantages only $(21 \%$ in 2015) was the most common situation in shared decision making.

Several decision aids to facilitate shared decision making for prostate cancer screening have been developed and most have been shown to improve patients' knowledge and involvement in the decision making process. ${ }^{23,24}$ There are multilevel barriers to implementing shared decision making, including competing demands during primary care physician visits ${ }^{25-27}$ and lack of system-level support, such as automated prompts. ${ }^{28,29}$ These barriers may be more prominent in limited-resource settings and could partly account for without discussion, than to the ACS, AUA, and ACP guidelines promoting shared decision making.

Compared with previous studies having more comprehensive measures of decision making, we observed a lower proportion of men who reported shared decision making. ${ }^{10,13}$ A previous nationally representative study of 375 men found that $70 \%$ of subjects underwent PSA testing with some discussion..$^{10}$ Another study of audio recorded physician-patient interactions from 5 clinics showed that $90 \%, 70 \%$, and $49 \%$ of visits included a discussion of the benefits, drawbacks, and controversies of PSA testing, respectively. ${ }^{13}$ There are several ways to measure shared decision making. ${ }^{32}$ Variations in shared decision making definitions could account for differences between our study and previous investigations and our results could be different if other measures were used. It appears, however, that the benefits of PSA testing are more commonly discussed than risks or uncertainties across studies and definitions. ${ }^{10,13}$

There are some limitations to the current study. First, we relied on self-reported data. The concordance between self-reported PSA testing and medical records is adequate, ${ }^{33}$ but the accuracy of self-reported shared decision making has not been assessed. Cognitive testing of the NHIS questionnaire indicates that some men may have answered questions based on their own beliefs about PSA testing rather than what had been communicated to them by a physician. ${ }^{34}$ Men's comprehension of these questions probably did not change 
Table 2. Adjusted Prevalence Ratios and 95\% CI Predicting Shared Decision Making Among Men Who Received PSA Testing in the Past Year for Routine Reasons, NHIS 2010 and 2015

\begin{tabular}{|c|c|c|c|c|}
\hline Characteristic & $\begin{array}{l}\geq 1 \text { Element } \\
\text { of SDM vs None } \\
\text { aPR }(95 \% \mathrm{Cl})\end{array}$ & $\begin{array}{l}\text { Advantages vs None } \\
\text { aPR }(95 \% \mathrm{Cl})\end{array}$ & $\begin{array}{c}\text { Advantages and } \\
\text { Disadvantages vs None } \\
\text { aPR }(95 \% \mathrm{Cl})\end{array}$ & $\begin{array}{l}\text { Full vs None } \\
\text { aPR }(95 \% \mathrm{Cl})\end{array}$ \\
\hline \multicolumn{5}{|c|}{ Among men with recent PSA testing ${ }^{a}$} \\
\hline \multicolumn{5}{|c|}{ Year } \\
\hline 2010 & $1.00[$ Reference] & 1.00 [Reference] & 1.00 [Reference] & 1.00 [Reference] \\
\hline 2015 & $1.04(0.98-1.11)$ & $0.82(0.71-0.96)^{b}$ & $0.94(0.79-1.12)$ & $1.51(1.28-1.79)^{b}$ \\
\hline \multicolumn{5}{|l|}{ Age } \\
\hline $50-64$ y & 1.00 [Reference] & 1.00 [Reference] & 1.00 [Reference] & 1.00 [Reference] \\
\hline $65-74$ y & $1.24(0.88-1.76)$ & $0.90(0.69-1.18)$ & $0.89(0.61-1.30)$ & $1.02(0.77-1.35)$ \\
\hline$\geq 75$ y & $0.99(0.63-1.54)$ & $0.96(0.07-1.32)$ & $0.78(0.52-1.18)$ & $0.95(0.69-1.30)$ \\
\hline \multicolumn{5}{|c|}{ Among men with nonrecent PSA testing ${ }^{c}$} \\
\hline \multicolumn{5}{|l|}{ Year } \\
\hline 2010 & 1.00 [Reference] & 1.00 [Reference] & 1.00 [Reference] & 1.00 [Reference] \\
\hline 2015 & $1.04(0.93-1.15)$ & $0.78(0.61-0.98)^{b}$ & $0.90(0.69-1.18)$ & $1.69(1.29-2.20)^{b}$ \\
\hline \multicolumn{5}{|l|}{ Age } \\
\hline $50-64$ y & $1.00[$ Reference $]$ & 1.00 [Reference] & 1.00 [Reference] & 1.00 [Reference] \\
\hline $65-74$ y & $1.08(0.90-1.30)$ & $1.41(0.91-2.20)$ & $0.95(0.54-1.65)$ & $0.75(0.49-1.16)$ \\
\hline$\geq 75$ y & $1.13(0.93-1.37)$ & $1.39(0.83-2.31)$ & $0.80(0.42-1.54)$ & $0.85(0.54-1.33)$ \\
\hline \multicolumn{5}{|c|}{ Among men with no PSA testing ${ }^{d}$} \\
\hline \multicolumn{5}{|c|}{ Year } \\
\hline 2010 & 1.00 [Reference] & 1.00 [Reference] & 1.00 [Reference] & 1.00 [Reference] \\
\hline 2015 & $0.97(0.76-1.24)$ & $0.91(0.60-1.37)$ & $1.27(0.74-2.18)$ & $0.90(0.56-1.43)$ \\
\hline \multicolumn{5}{|l|}{ Age } \\
\hline $50-64$ y & 1.00 [Reference] & 1.00 [Reference] & 1.00 [Reference] & 1.00 [Reference] \\
\hline $65-74$ y & $0.99(0.60-1.62)$ & $1.07(0.40-2.86)$ & $0.62(0.24-1.55)$ & $1.04(0.53-2.01)$ \\
\hline$\geq 75$ y & $0.85(0.45-1.58)$ & $0.45(0.13-1.60)$ & $1.05(0.37-2.93)$ & $1.47(0.70-3.10)$ \\
\hline \multicolumn{5}{|c|}{ aPR = adjusted prevalence ratio; NHIS = National Health Interview Survey; PSA = prostate-specific antigen; SDM = shared decision making. } \\
\hline $\begin{array}{l}\text { Note: Each model i } \\
\text { a Model includes 2,5 } \\
\text { b Statistically signific } \\
\text { ' Model includes } 1,7 \\
{ }^{d} \text { Model includes } 4,2\end{array}$ & $\begin{array}{l}\text { sted for: age, survey year, } \\
\text { en; } 487 \text { men excluded fron } \\
P<.05 \text {. } \\
\text { en; } 352 \text { men excluded fron } \\
69 \text { men excluded from eac }\end{array}$ & $\begin{array}{l}\text { thnicity, educational attainment, } \\
\text { model based on missing educat } \\
\text { model based on missing educat } \\
\text { del based on missing educational }\end{array}$ & $\begin{array}{l}\text { ance type, immigration status, and g } \\
\text { attainment and immigration data. } \\
\text { attainment and immigration data. } \\
\text { nment and immigration data. }\end{array}$ & aphic region. \\
\hline
\end{tabular}

with time, and thus did not influence the temporal patterns assessed. The NHIS data do not contain information about the timing of shared decision making, so we were unable to directly assess the impact of shared decision making prevalence on PSA testing behaviors. Also, we did not have information on the quality and medium (for example, brochure or conversation) of shared decision making delivery or other characteristics of shared decision making including patient preferences or involvement. ${ }^{32,35}$ The present study relied on self-reported necessary, but not sufficient, components of shared decision making. Despite this limitation and others noted above, our results provide useful and contemporary information on nationwide patterns of shared decision making.

In conclusion, this study shows about $60 \%$ of men with recent PSA testing reported receiving at least 1 component of shared decision making in 2010 and 2015. During this time, there was a slight shift toward full shared decision making and away from discussions that only emphasized the advantages of PSA testing. This change may reflect a modest increase in recognition and awareness on the part of health care practitioners of the importance of communicating not only benefits, but also risks and uncertainties of PSA screening for prostate cancer. But contrary to guidelines, many men receiving PSA testing still do not receive shared decision making and only 1 in 10 men with no PSA test history received $\geq 1$ elements of shared decision making. New and innovative strategies are needed to achieve more widespread application of shared decision making.

To read or post commentaries in response to this article, see it online at http://www.AnnFamMed.org/content/16/2/139.

Key words: decision making, early detection of cancer, prostatespecific antigen

Submitted May 2, 2017; submitted, revised, August 25, 2017; accepted October 10, 2017. 
Funding support: This work was supported by the American Cancer Society's Intramural Research Department.

Supplementary materials: Available at http://www.AnnFamMed. org/content/16/2/139/suppl/DC1/.

\section{References}

1. Moyer VA; US Preventive Services Task Force. Screening for prostate cancer: U.S. Preventive Services Task Force recommendation statement. Ann Intern Med. 2012;157(2):120-134.

2. US Preventive Services Task Force. Draft recommendation statement, prostate cancer: screening. https://www.uspreventiveservicestaskforce. org/Page/Document/RecommendationStatementDraft/prostatecancer-screening1. Published 2017. Accessed Apr 11, 2017.

3. Wolf AM, Wender RC, Etzioni RB, et al; American Cancer Society Prostate Cancer Advisory Committee. American Cancer Society guideline for the early detection of prostate cancer: update 2010. CA Cancer J Clin. 2010;60(2):70-98.

4. Carter HB, Albertsen PC, Barry MJ, et al. Early detection of prostate cancer: AUA Guideline. J Urol. 2013;190(2):419-426.

5. Qaseem A, Barry MJ, Denberg TD, Owens DK, Shekelle P; Clinical Guidelines Committee of the American College of Physicians. Screening for prostate cancer: a guidance statement from the Clinical Guidelines Committee of the American College of Physicians. Ann Intern Med. 2013;158(10):761-769.

6. US Preventive Services Task Force. Screening for prostate cancer: U.S. Preventive Services Task Force recommendation statement. Ann Intern Med. 2008;149(3):185-191.

7. Kane HL, Halpern MT, Squiers LB, Treiman KA, McCormack LA. Implementing and evaluating shared decision making in oncology practice. CA Cancer J Clin. 2014;64(6):377-388.

8. Han PK, Kobrin S, Breen N, et al. National evidence on the use of shared decision making in prostate-specific antigen screening. Ann Fam Med. 2013;11(4):306-314.

9. Leyva B, Persoskie A, Ottenbacher A, et al. Do men receive information required for shared decision making about PSA testing? Results from a National Survey. J Cancer Educ. 2016;31(4):693-701.

10. Hoffman RM, Couper MP, Zikmund-Fisher BJ, et al. Prostate cancer screening decisions: results from the National Survey of Medical Decisions (DECISIONS study). Arch Intern Med. 2009;169(17): 1611-1618.

11. Han PK, Coates RJ, Uhler RJ, Breen N. Decision making in prostatespecific antigen screening National Health Interview Survey, 2000. Am J Prev Med. 2006;30(5):394-404.

12. Leader A, Daskalakis C, Braddock CH III, et al. Measuring informed decision making about prostate cancer screening in primary care. Med Decis Making. 2012;32(2):327-336.

13. Feng B, Srinivasan M, Hoffman JR, et al. Physician communication regarding prostate cancer screening: analysis of unannounced standardized patient visits. Ann Fam Med. 2013;11(4):315-323.

14. Jemal A, Fedewa SA, Ma J, et al. Prostate cancer incidence and PSA testing patterns in relation to USPSTF screening recommendations. JAMA. 2015;314(19):2054-2061.

15. US Department of Health and Human Services. National Health Interview Survey, Survey Description. Hyattsville, Maryland: National Center for Health Statistics; 2016.

16. National Center for Health Statistics, Division of Health Interview Statistics. National health interview survey; questionnaires, datasets, and related documentation. http://www.cdc.gov/nchs/nhis/ nhis_questionnaires.htm. Accessed Dec 1, 2014.

17. Bieler GS, Brown GG, Williams RL, Brogan DJ. Estimating modeladjusted risks, risk differences, and risk ratios from complex survey data. Am J Epidemiol. 2010;171(5):618-623.
18. Schröder FH, Hugosson J, Roobol MJ, et al; ERSPC Investigators. Screening and prostate-cancer mortality in a randomized European study. N Engl J Med. 2009;360(13):1320-1328.

19. Andriole GL, Crawford ED, Grubb RL III, et al; PLCO Project Team. Mortality results from a randomized prostate-cancer screening trial. N Engl J Med. 2009;360(13):1310-1319.

20. Ablin RJ. The United States Preventive Services Task Force recommendation against prostate-specific antigen screening-point. Cancer Epidemiol Biomarkers Prev. 2012;21(3):391-394.

21. Brett AS, Ablin RJ. Prostate-cancer screening-what the U.S. Preventive Services Task Force left out. N Engl J Med. 2011;365(21): 1949-1951.

22. Prabhu V, Lee T, Loeb $S$, et al. Twitter response to the United States Preventive Services Task Force recommendations against screening with prostate-specific antigen. BJU Int. 2015;116(1):65-71.

23. Taylor KL, Williams RM, Davis K, et al. Decision making in prostate cancer screening using decision aids vs usual care: a randomized clinical trial. JAMA Intern Med. 2013;173(18):1704-1712.

24. Volk RJ, Hawley ST, Kneuper S, et al. Trials of decision aids for prostate cancer screening: a systematic review. Am J Prev Med. 2007; 33(5):428-434.

25. Davis K, Haisfield L, Dorfman C, Krist A, Taylor KL. Physicians' attitudes about shared decision making for prostate cancer screening. Fam Med. 2011;43(4):260-266.

26. Friedberg MW, Van Busum K, Wexler R, Bowen M, Schneider EC. A demonstration of shared decision making in primary care highlights barriers to adoption and potential remedies. Health Aff (Millwood). 2013;32(2):268-275.

27. Gravel K, Légaré F, Graham ID. Barriers and facilitators to implementing shared decision-making in clinical practice: a systematic review of health professionals' perceptions. Implement Sci. 2006;1:16.

28. Elwyn G, Scholl I, Tietbohl C, et al. "Many miles to go ...": a systematic review of the implementation of patient decision support interventions into routine clinical practice. BMC Med Inform Decis Mak. 2013;13(Suppl 2):S14.

29. Sepucha KR, Simmons LH, Barry MJ, Edgman-Levitan S, Licurse AM, Chaguturu SK. Ten years, forty decision aids, and thousands of patient uses: shared decision making at Massachusetts General Hospital. Health Aff (Millwood). 2016;35(4):630-636.

30. Volk RJ, Spann SJ, Cass AR, Hawley ST. Patient education for informed decision making about prostate cancer screening: a randomized controlled trial with 1-year follow-up. Ann Fam Med. 2003;1(1):22-28.

31. Fedewa SAWE, Ward EM, Brawley O, Jemal A. Recent patterns of prostate-specific antigen testing for prostate cancer screening in the United States. JAMA Intern Med. 2017;177(7):1040-1042.

32. Charles C, Gafni A, Whelan T. Shared decision-making in the medical encounter: what does it mean? (or it takes at least two to tango). Soc Sci Med. 1997;44(5):681-692.

33. Rauscher GH, Johnson TP, Cho YI, Walk JA. Accuracy of selfreported cancer-screening histories: a meta-analysis. Cancer Epidemiol Biomarkers Prev. 2008;17(4):748-757.

34. National Health Interview Survey. Cognitive interview evaluaton of the 2015 NHIS Cancer Control Supplement. https://wwwn.cdc. gov/qbank/report/Willson_2014_NCHS_NHIS.pdf. Published 2015. Accessed Feb 2, 2017.

35. Sepucha KR, Scholl I. Measuring shared decision making: a review of constructs, measures, and opportunities for cardiovascular care. Circ Cardiovasc Qual Outcomes. 2014;7(4):620-626. 